\title{
Identification and Adaptation of the Russian System of Ownership Relations into the Modern World's Legal and Economic Spaces
}

\author{
Submitted 05/04/19, 1st revision 22/04/19, 2nd revision 25/05/19, accepted 14/06/19
}

\author{
O.N. Dmitriev ${ }^{1}$
}

\begin{abstract}
:
Purpose: A provision has been made regarding the Russian system of ownership and its insufficient harmonization with similar systems adopted in developed countries, which also have significant drawbacks. The complex task has been set from its rationalization as such and counters rational harmonization with the systems of the leading countries in the world.

Design/Methodology/Approach: The conceptual structure of the system of ownership relations has been introduced for this purpose. It is like the conceptual basis of complex systems engineering, economic, and legal interpretations of the processor (the mechanism), the implementation of static and dynamic relations of persons and objects in the civil economic space.
\end{abstract}

Findings: This concept is based on the introduction of a special class of structurally and procedurally typed systems that are given the character of the vocabulary of the metalinguistic converged description of the verbal processor for manipulating persons in relation to objects and the verbal dependence of these objects on these persons.

Practical Implications: A conceptual approach to its rationalization and harmonization has been formed based on the idea of a unified global structure of representing the system of ownership relations.

Originality/Value: Argued the estimation of the low quality of the modern Russian system of ownership relations (another used term - property relations) and its normative legal representation.

Keywords: Legal space, economic space, ownership relations, system analysis, formalization, harmonization and adaptation of ownership relations.

JEL Classification: K11, K12, K13, K40.

Paper type: Research article.

\footnotetext{
${ }^{1}$ PhD (Engineering), Full Doctor (Economics), Professor of Management, Professor at HighTechnology Industry Production Management and Marketing Department, Moscow Aviation Institute (National Research University), E-mail: olegdmitriev@yandex.ru
} 


\section{Introduction}

It is axiomatic that effective management of the modern high-tech and high-tech production under post-industrialization and globalization can be organized and carried out only if an adequate identification of the managing object is performed in some canonized form. This form must be suitable for the subsequent use in the development of management decisions regarding the object of management with their justification and with their adoption. This view should allow to identify the object both statically and dynamically. Such structuring can have several levels or stages, which in fact is always characteristic of such complex objects as economics. At present, the situation with the fundamental construction of the economy (the system of ownership relations) in the current Russian conditions looks, at first sight, rather narrow-minded and bureaucratic, as something natural and non-threatening, and with a more thorough, scientific consideration, the situation looks pitiable, which is fraught with catastrophic consequences. The appropriate problematic finds its expression integrally in the following:

$\checkmark$ in the essential aspect, the Russian system of ownership relations has the character of an internally contradictory and incomplete system with a significant number of incorrect components. Perhaps, it would not even be too much an exaggeration to argue that the existence of a systematic organization of Russian ownership relations in a strict sense looks rather dubious;

$\checkmark$ in terms of a regularity (may be said model, processor or scenario) of the legal and economic descriptive representation, it practically does not exist, which makes it impossible to identify errors in its construction and improve on the basis of scientific approaches and methods;

$\checkmark$ the reflection of the Russian system of ownership relations in laws and regulations contains a critical mass of deficiencies in the form of incompleteness, mutual inconsistency, excessive dynamism and inaccuracy of the components, as well as non-transparency. It is seen a representative example of the analysis of such general flaws and proposals for remedying the situation, in particular, in Bodrunov, Dmitriev \& Koval'kov (2002), Dmitriev (2018a), Dmitriev \& Novikov (2018), Dmitriev (2018b) and with an emphasis on the tax system of the Russian Federation in some cases;

$\checkmark$ the system of ownership relations in the mental space of Russian subjects of legal relations is additionally and subjectively distorted due to their mass incompetence and the presence of ideological and psychological stereotypes. This is typical for the majority of individuals, including high-level managers and leading entrepreneurs. It seems fair to say figuratively that every individual in Russia has a vision of his own, a unique system of ownership relations, which is partially similar to the vision of others. In addition, adherence to scientific visions and compliance with the law is not a strict behavioral norm in modern Russian society; 
$\checkmark$ the Russian system of ownership relations is insufficiently harmonized with the systems of ownership relations in the most developed countries. Therefore, the Russian people, who are operationally abroad, objectively become legal schizophrenics. The situation is similar with foreigners who started operating in Russia.

Naturally, the ownership relations system disorder is a serious crisis forming factor in these conditions (Zolotova, 2017). This is most clearly manifested in the conduct of marketing operations, when the rights and restrictions of contract parties take on the character of vague and constructs of dubious correctness. We can see the exact same visible situation in the field of institutional activity, where many designs are based on erroneous constructions of the system of ownership relations. It should be noted that such problems are not unique only concerning modern Russia. In many countries these imperfections appear, even in the leading countries of the world economy, although in different forms and to varying degrees. Therefore, the problem of identification, rationalization and mutual adaptation of the systems of ownership relations is obviously international in nature and subject to awareness and correct resolution.

The situation is seen as an ideal when there will be a unified, optimized or at least rationalized system of ownership relations in the world, something like a specialized "Esperanto language" for a system of ownership relations. There is no doubt that a collection of descriptions of ownership relations systems would be as useful as it is difficult to compose for countries with developed high-tech production and their comparison. Therefore, we will choose the Russian economy as a testing ground and demonstrate how this kind of productive description can look like.

\section{Results}

\subsection{The forerunners and the applicability of their developments}

Unfortunately, no conceptual method has been proposed until now that could describe the systemic nature of the interaction between market actors and marketable products, including in relation to modern Russian conditions. The analysis of the available publications on the identification of ownership relations gave rather discouraging results. It is obvious that it is physically impossible to study all or most of the publications of forerunners on this topic, as well as on the other.

Therefore, highly reputed and representative repositories of "respectable" publications were chosen for the analysis, first of all, monographs and dissertations, which make it possible to carry out initial sounding through electronic catalogs. This kind of polygon storage was chosen for Russia (Russian State Library - RSL, www.rsl.ru) and for the whole world (Library of Congress of USA, LoC, www.loc.gov). The latter was connected, among other things, with the language 
capabilities of the author of the study, as well as with the free remote access mode to directories.

In the RSL as of middle of December 2018, it was revealed an insignificant number of large-scale publications on the issues under discussion about ten to fifteen in the last 20 years, including such as Sukhanov (1991), Gutman et al. (2002), Al'pidovskaya \& Sokolov (2015), Tsorgaeva (2014), Grabova (2007), Yakunina (2006). The issues of the representation of the system of ownership relations are mainly discussed in the form of local direct non-agreed quotations and minor rephrasing of the Civil Code of the Russian Federation or we can find it in the annex to private object and subject areas in many other specialized local publications. As a rule, such publications have the character of low-volume textbooks for universities. In general, the issues of a formalized representation of the system of ownership relations are not even posed in the identified publications.

At the same time, the publications allegedly did not exist in the LoC of USA, on obvious keywords, including "representation of ownership relations", "representation of property relations" even in Russian language: a "red" message known to visitors of the site appeared for the requests "Your search found no results". The author attributes this phenomenon either to unsuccessful indexing by keywords in the database or to his own ignorance of the American-language original term, including jargon. Nevertheless, the search phenomenon seems quite symptomatic. Based on the pessimistic nature of the results of the search for analogues and prototypes, we have to focus on the scheme "tabula rasa".

\subsection{Structuring the economic sphere and legal relations system}

Now we consider the top level of the structurization among all of them, which is the most similar with the production relations (corresponding with the political economy categories), if the production is any act or omission of persons, leading to the creation of new results of activity or natural processes (alteration or destruction of existing objectified, i.e. having a material embodiment).

Accordingly, it is need to structure the economy to an arbitrary point in time in a typical way in certain aspect and in some legal categories by entering the so-called ownership relations system in which concepts, including those of its structural statics and dynamics, and let's begin to represent the relationship of subjects of the market economy. At the same time, we will proceed from the assumption that certain objects are created, changed and destroyed in the economy; it is the objectified results of actions or inactions of subjects.

In this system, it is necessary to select objects set and set of the links between them. We consider a generalized system, implying the definition of objects of legal relations, subjects of legal relations and legal relations. 
By objects of legal relations, we mean any possible for distinction and separation object from the material environment in respect of which may occur, change and disappear regulatory relations envisaged by law (rights) and / or debt limit of the acceptation or the purpose of the obligations, implementation of obligations and liability of legal entities. Rights are acceptable opportunities for implementation and / or the failure of any actions. The set of objects of the legal relations includes:

$\checkmark$ material objects;

$\checkmark$ the ability to carry out or to exercise any actions applying to these objects.

The set of rights and obligation restrictions forms a legal relationship. In general, we will proceed from the fact that obligations are accepted, assigned, indispensable (that is, existing a priori and in all circumstances) or due to certain conditions and fixed in an objective form (including in a legislative act or contract, imposing obligations) the need for the subject of legal relations to take or not to take on his part certain actions. Therefore, the obligations can be indispensable, forcibly and appointed from outside by another subject of legal relations or a character voluntarily assumed by it.

Accordingly, the duties are a list or composition of the already mentioned actions or omissions stipulated by the obligations. Based on the above, it is obvious that the obligations without duties cannot exist and also vice versa. The execution of obligations by means of implementation of their agreed duties is the execution of actions or omissions of the character mentioned, i.e. implementation of duties. Therefore, the execution of obligations through the implementation of duties is a meaningful process of carrying out of the certain operations or the process of suspending of some ones. The not quite correct phrase "execution of duties" is sometimes used, taking into account such rigid synchronization and interconnectedness of the concepts of obligations and duties, which in its meaning is no different from the execution of obligations, for example, by means of their cancellation.

There is a concept of their termination with regard to obligations, which may be associated with their execution, the impossibility of execution and with occurrence of some other conditions. Finally, responsibility should again be understood as obligatory restrictions, but only already arising solely in the case of a non-execution or improper execution by the subject of a legal relationship of its initial obligations. Therefore, the liability nature of responsibility envisages the additional set of obligations and responsibilities, which envisages to take actions or not to take ones only in case of violation (in terms of composition, completeness, terms, effectiveness, etc.) of the process of primary duties implementation.

In particular, responsibility has an interesting procedural feature: it cannot be final according to the condition of an offensive in principle, since non-execution or improper execution of obligations within the framework of the incurred responsibility should give rise to a new responsibility and to infinity. In other words, 
a tuple of non-executable responsibilities has the character of a countable set, if we use the concepts of functional analysis.

As it is understood, this is unacceptable in practice, and therefore it is considered that the obligations arising from the agreed responsibility for the final number of consecutively initiated responsibilities are executed without fail or the tuple of responsibilities ends in one of them, and no further responsibility is established for non-execution or improper execution of obligations under the last agreed liability.

Obligations can arise, change and terminate (including in connection with the completion of their execution) in full and in part, unconditionally or conditionally, jointly (by agreement of the subjects of legal relations) or unilaterally. In turn, the subjects of legal relations will be defined as persons who have or may have different rights and / or obligatory limitations with respect to objects of legal relations under certain conditions.

Objects of legal relations and subjects of legal relations form in conjunction with legal relations a system of legal relations. Therefore, the system of legal relations is structural in nature, and includes subjects, objects, and relations of the communication between them.

Objects of legal relations, being the passive elements of this system, do not interrelate with each other in terms of legal relations. Therefore, it is legitimate to consider only two categories of relations in the general case: legal relations of subjects of legal relations concerning objects of legal relations and legal relations between subjects of legal relations. However, it is not excluded that certain subjects of legal relations may be given the simultaneous status of objects of legal relations under certain circumstances.

Nonetheless, the legal relations are a very broad concept and takes far beyond the scope of persons' interaction, and therefore distinguish civil law from among them. Legislative regulation on the rights and obligation restrictions of subjects of legal relations within their civil legal relations is presented in Part II of the Civil Code of the Russian Federation. However, they are formally presented here only in the context of contractual relations of subjects of legal relations (creditors and debtors), which unacceptably narrows the agreed area of legislative regulation and does not allow to go beyond it and generate definitions for the general case.

The closest to the objects of property in legal and economic terms according to the Russian legislation are the so-called objects of civil law, which are enumerated vaguely and not exhaustively introduced by article 128 of the Civil Code of the Russian Federation. Many real-life objects or those able to become so in the foreseeable future are simply not mentioned (even the construction "and others" is not available). However, the objects of civil rights include non-material benefits (Chapter 8 of the Civil Code of the Russian Federation - Articles 150-152), many of 
which clearly cannot be an object of legal relation. At the same time, it is clear that the objects of civil law are obviously a narrower set, rather than objects of legal relations.

In fact, civil law regulates only relations between persons engaged in entrepreneurial activity, or relations with their participation in accordance with its own regulation. Civil law does not apply to property relations based on administrative or other authority subordination of one party to the other, including tax and other financial and administrative relations, unless otherwise provided by statutory provisions.

It would be incorrect to focus only on civil legal relations when building the conceptual structure of the system of ownership relations and further describing the essence and forms of marketing. The reason is that many of the actions or omissions are not directly related to the business sector, but they are not excluded when describing some special marketing problems. In particular, interpreted civil legal relations are formally and deliberately excluded from consideration of the supply of marketable products by one non-profit organization to another one.

Therefore, legal relations incorporate the civil ones and it can be recognized that they are a narrowing of many legal relations by excluding them, which have a noncontractual nature. Russia also has a system of proprietary interest relations. It seems to be identical within the meaning of the system of civil legal relations, but this is only a legal hypothesis.

\subsection{Localization and structural representation of the system of ownership relations}

Now we relate civil legal relations and ownership relations. We specify that the ownership relations are not generally a special case or a local group of civil relations and they are not identical in any case. The ownership relations are a local type of legal relations defining some special rights and special obligatory restrictions for subjects of ownership in relation to objects of ownership. Unfortunately, strict rules for separating ownership relations among legal relations have not been introduced, and therefore it is necessary to focus not on the comparative distinction between their definitions but on the definitions themselves. That is, ownership relations extend to the relations between the subjects in terms of the ownership and also between them because of their own character. The objects of ownership are understood as objects of legal relations for which ownership relations can be established, changed or canceled.

From the above, it is seen that the definitions of objects of ownership, subjects of ownership and ownership relations are forced to be recursive, interlinked. It should be noted that it is permissible to include an even more generalized term in comparison with the objects of legal relations. This term is the object. In fact, objectively, there are only some few objects that allow interpretation as objects of 
legal relation. In turn, the right of ownership may be distributed to some of the objects of legal relations. That is, every object of ownership is an object of legal relations in the general case, but not every object of legal relations is necessarily an object of someone's ownership. A similar mutually ambiguous relationship is typical for objects of general interest and objects of legal relations. Therefore, it is necessary to consider the sequential decomposition of the system of some systems for positioning the system of ownership relations, illustrated in Figure 1.

At the same time, there are two interpretations of the system of ownership relations: the strict one (which was given above) and the broad one. The latter includes objects of proprientary interest rights, subjects of proprientary interest rights and relations of proprientary interest rights, which together form the system of relations of proprientary interest rights. Therefore, the system of ownership relations in the broad interpretation is a system of relations of proprientary interest.

Figure 1. Hierarchical correlation of systems and allocation of the system of ownership relations

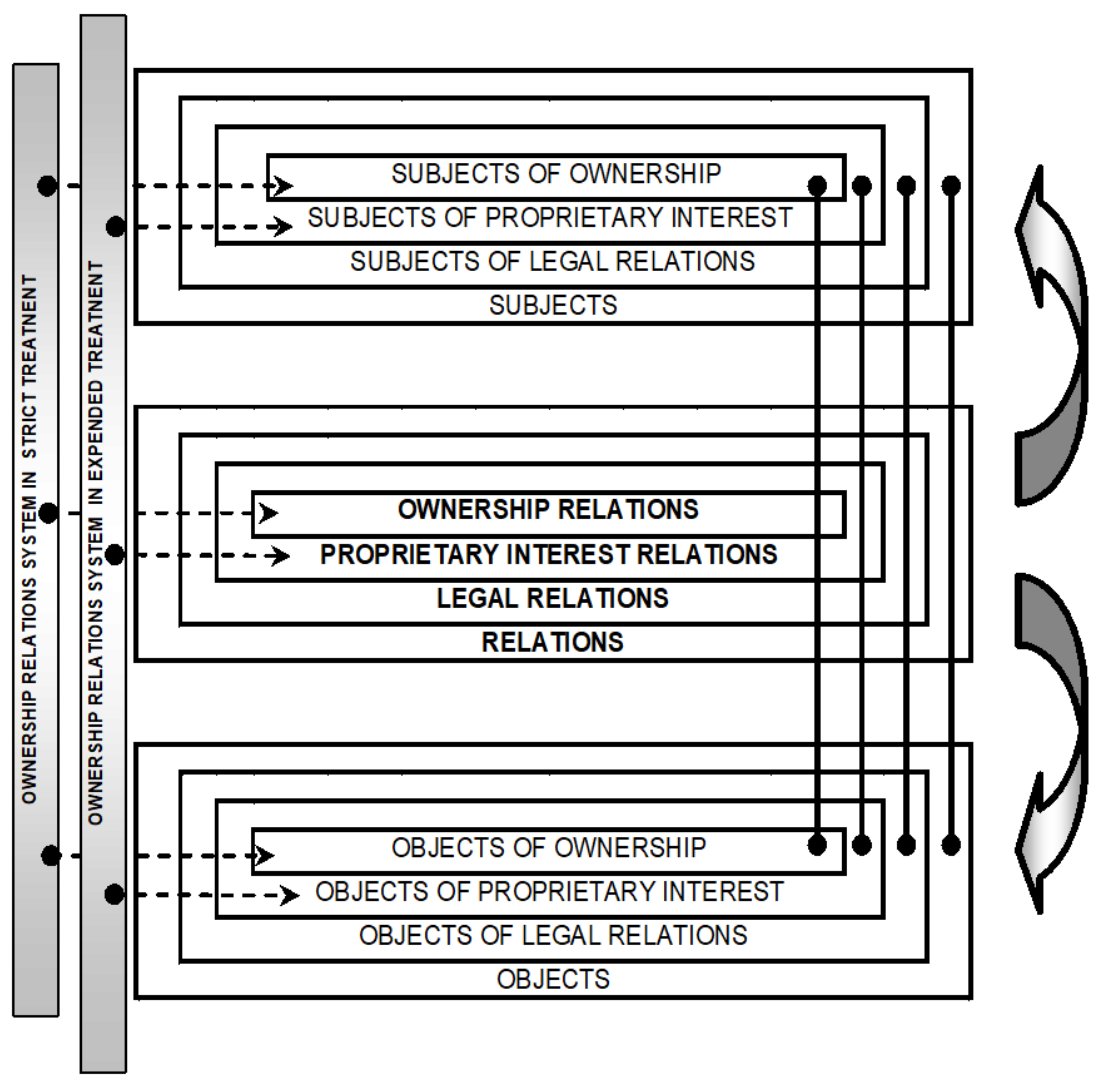


The concept of proprientary interest law has been introduced in relation to the Russian economy. Although it is not directly defined, it is indirectly interpreted through a description of its types. It seems permissible to assume that property rights can be represented as a combination of several systems of property relations. These are the following six types of proprientary interest rights:

$\checkmark$ the ownership right (or full ownership right) - it is considered mainly;

$\checkmark$ the economic jurisdiction or economic conduct right (see Articles 294, 295 of the Civil Code of the Russian Federation). Also, there is the term "full economic management" in the clauses 5 and 6 of Article 6 of the Civil Code of the Russian Federation;

$\checkmark$ the right of operational management (see Articles 296, 297 of the Civil Code of the Russian Federation);

$\checkmark$ the right to lifelong inherited possession of a land plot or right of life heritable tenure of a ground area (see Article 265 of the Civil Code of the Russian Federation);

$\checkmark$ the right of perpetual (permanent) use of a land plot that is in state or municipal ownership, and some of the facilities infrastructure of real estate (see Article 268 of the Civil Code of the Russian Federation);

$\checkmark$ the servitudes, i.e. the right of limited use of someone else's estate (see Articles 274, 277 of the Civil Code of the Russian Federation) - first of all, in terms of compensation for use.

We single out the so-called objects of the first and second kind as objects included in the system of ownership relations:

$\checkmark$ objects of the first kind are some subjects (they are called persons in this case) who are authorized to perform or not to perform certain rational actions (or inaction) in relation to other objects of the first and second kind included in the system, and do so in the general case;

$\checkmark$ objects of the second kind are objects, firstly, non-subjects. Secondly, in relation to which the indicated actions or inactions can be performed and / or actually committed by objects of the first kind, i.e. known or subject to such exposure. At the same time, some impact is not only not excluded in the opposite direction from an object of the second kind in the direction of an object of the first kind, but is also typical.

The objects of the above mentioned kinds have the following distinctions:

$\checkmark$ by existence: existing and non-existent;

$\checkmark$ by the nature of temporal existence or by belonging to existence for a specific period of time, they are divided into existing or non-existent in the past (up to the present), existing or non-existent in the present (presently) and existing and non-existent in the future (after the present moment), i.e. which can or they cannot exist. 
There are 12 possible options for their independent formal consideration as shown in Table 1.

Table 1. Possible options for objects in the system of property relations

\begin{tabular}{|c|c|c|c|}
\hline $\begin{array}{l}\text { Conditional } \\
\text { end-to-end } \\
\text { number }\end{array}$ & Object kind & Existence & $\begin{array}{l}\text { Period } \\
\text { of time }\end{array}$ \\
\hline 1 & \multirow{6}{*}{ First } & \multirow{3}{*}{ Existing } & Past \\
\hline 2 & & & Present \\
\hline 3 & & & Future \\
\hline 4 & & \multirow{3}{*}{ Non-existent } & Past \\
\hline 5 & & & Present \\
\hline 6 & & & Future \\
\hline 7 & \multirow{6}{*}{ Second } & \multirow{3}{*}{ Existing } & Past \\
\hline 8 & & & Present \\
\hline 9 & & & Future \\
\hline 10 & & \multirow{3}{*}{ Non-existent } & Past \\
\hline 11 & & & Present \\
\hline 12 & & & Future \\
\hline
\end{tabular}

It should be noted that the existence or non-existence of objects of the first and second kinds can be recognized as independent in some sense, if it is not taking into account situations conventionally when objects of the first kind were used to create objects of the second kind or vice versa. In the first case, we are talking about the production of objects of the first kind by objects of the second kind in particular, and in the second case about the use of objects of the second kind by objects of the second kind in the first production and economic activities with their consumption, or using objects of the second kind when establishing objects of the first kind. Therefore, in principle, all possible combinations can take place for each of the selected time segments (past, present and future) as shown in Table 2.

We select just a few among the variety connections between these objects within the framework of this system of ownership relations and confine them. Accordingly, there are:

$\checkmark$ the connections of the first kind regulate the legality (admissibility and / or compulsory) of the implementation of a certain group of actions or omissions of objects of the first kind in relation to other objects of the second kind including in the system. Therefore, connections of the second kind have the nature of regulations, they are regulating connections and they have the form of a dyadic jurisprudence connection "object of the first kind object of the second kind";

$\checkmark$ the connections of the second kind are those implying the obligation or the possibility of carrying out certain legitimate verbal actions of objects of the 
first kind with respect to objects of the second kind. However, such actions are not necessarily carried out in the general case, because they can be fundamentally or completely unrealizable. In principle, the communication of the first kind can be empty, i.e. absent altogether: for example, not foreseen. The connection of the second kind is also a dyadic physical connection of the type "object of the first kind - object of the second kind".

Table 2. Possible combinations of options for objects in the system of ownership relations

\begin{tabular}{|c|c|c|c|}
\hline \multirow{2}{*}{$\begin{array}{l}\text { Conditional } \\
\text { end-to-end } \\
\text { number }\end{array}$} & \multirow{2}{*}{ Period of time } & \multicolumn{2}{|l|}{ Object kind } \\
\hline & & First & Second \\
\hline 1 & \multirow{4}{*}{ Past } & \multirow{2}{*}{ Existing } & Existing \\
\hline 2 & & & Non-existent \\
\hline 3 & & \multirow{2}{*}{ Non-existent } & Existing \\
\hline 4 & & & Non-existent \\
\hline 5 & \multirow{4}{*}{ Present } & \multirow{2}{*}{ Existing } & Existing \\
\hline 6 & & & Non-existent \\
\hline 7 & & \multirow{2}{*}{ Non-existent } & Existing \\
\hline 8 & & & Non-existent \\
\hline 9 & \multirow{4}{*}{ Future } & \multirow{2}{*}{ Existing } & Existing \\
\hline 10 & & & Non-existent \\
\hline 11 & & \multirow{2}{*}{ Non-existent } & Existing \\
\hline 12 & & & Non-existent \\
\hline
\end{tabular}

We include the following distinctions for the first and the second kind of connections (as for the objects):

$\checkmark$ by existence: existing and non-existent. We divide existing connections into real and potential ones;

$\checkmark$ by the nature of the time existence: existing or non-existent in the past (up to the present), existing or non-existent in the present (at the present moment of time) and existing or non-existent in the future (after the present moment of time), i.e. whether or not able to exist.

There are 18 possible combinations of variants for connections with their independent formal consideration (Table 3). However, relations are strictly interconnected by the conditionality of their existence, in contrast to the case of objects. However, the first and the second kind of connections are rigidly interrelated through the imposed one-way mutual regulation, and the first kind of connections are permissive for the second one (for example, only the presence of a real connection of the first kind can be combined with the presence of a real connection of the second kind). 
Table 3. Possible combinations for connections in the system of ownership relations

\begin{tabular}{|c|c|c|c|c|}
\hline $\begin{array}{l}\text { Conditional } \\
\text { end-to-end } \\
\text { number }\end{array}$ & $\begin{array}{l}\text { Kind } \\
\text { of } \\
\text { connection }\end{array}$ & \multicolumn{2}{|l|}{ Actual availability } & $\begin{array}{l}\text { Period } \\
\text { of time }\end{array}$ \\
\hline 1 & \multirow{9}{*}{ First } & \multirow{3}{*}{\multicolumn{2}{|c|}{ Existing }} & Past \\
\hline 2 & & & & Present \\
\hline 3 & & & & Future \\
\hline 4 & & \multirow{6}{*}{ Existing } & Real & \multirow{2}{*}{ Past } \\
\hline 5 & & & Potential & \\
\hline 6 & & & Real & \multirow{2}{*}{ Present } \\
\hline 7 & & & Potential & \\
\hline 8 & & & Real & \multirow{2}{*}{ Future } \\
\hline 9 & & & Potential & \\
\hline 10 & \multirow{9}{*}{ Second } & \multirow{3}{*}{\multicolumn{2}{|c|}{ Non-existent }} & Past \\
\hline 11 & & & & Present \\
\hline 12 & & & & Future \\
\hline 13 & & \multirow{6}{*}{ Existing } & Real & \multirow{2}{*}{ Past } \\
\hline 14 & & & Potential & \\
\hline 15 & & & Real & \\
\hline 16 & & & Potential & Present \\
\hline 17 & & & Real & \\
\hline 18 & & & Potential & Future \\
\hline
\end{tabular}

Therefore, there are 10 options for combinations of connections in total as shown in Table 4.

Table 4. Possible combinations of variants of connections in the system of ownership relations

\begin{tabular}{|c|c|c|c|c|c|}
\hline \multirow{3}{*}{ 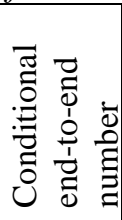 } & \multirow{3}{*}{$\begin{array}{l}\text { Period } \\
\text { of time }\end{array}$} & \multicolumn{4}{|c|}{ Kind of connections } \\
\hline & & \multicolumn{2}{|l|}{ First } & \multicolumn{2}{|l|}{ Second } \\
\hline & & \multicolumn{2}{|c|}{ Actual availability } & \multicolumn{2}{|c|}{ Actual availability } \\
\hline 1 & \multirow{4}{*}{ Past } & \multicolumn{2}{|c|}{ Non-existent } & \multicolumn{2}{|c|}{ Non-existent } \\
\hline 2 & & \multirow{3}{*}{ Existing } & & \multirow{3}{*}{ Existing } & Real \\
\hline 3 & & & Real & & Potential \\
\hline 4 & & & Potential & & Potential \\
\hline 5 & \multirow{4}{*}{ Present } & \multicolumn{2}{|c|}{ Non-existent } & \multicolumn{2}{|c|}{ Non-existent } \\
\hline 6 & & \multirow{3}{*}{ Existing } & & \multirow{3}{*}{ Existing } & Real \\
\hline 7 & & & Real & & Potential \\
\hline 8 & & & Potential & & Potential \\
\hline 9 & \multirow{2}{*}{ Future } & \multicolumn{2}{|c|}{ Non-existent } & \multicolumn{2}{|c|}{ Non-existent } \\
\hline 10 & & Existing & Potential & Existing & Potential \\
\hline
\end{tabular}


Now it is left to match the options for objects and connections, i.e. to form combinations of combinations. In this case, we confine to the undoubted fact that a change in the state of the system of ownership relations can occur only in the present tense, since the past time has passed and the future has not yet come. Therefore, it is legitimate to confine only to the present.

Accordingly, here is the static structuring of the system of ownership relations, reflected in Table 5. This structuring in a typical manner extends to objects localized into a group when considering specific management tasks of a marketing type.

Table 5. Possible options for combinations of objects and relationships of the first and second kinds (selected time period: present)

\begin{tabular}{|c|c|c|c|c|c|c|c|c|c|c|}
\hline \multirow{3}{*}{$\begin{array}{l}\text { Condi- } \\
\text { tional } \\
\text { end-to- } \\
\text { end } \\
\text { number }\end{array}$} & \multicolumn{10}{|c|}{ Structural element of system } \\
\hline & \multicolumn{4}{|c|}{ Objects } & \multicolumn{6}{|c|}{ Connections } \\
\hline & Kind & $\begin{array}{l}\text { Actual } \\
\text { availa- } \\
\text { bility }\end{array}$ & Kind & $\begin{array}{l}\text { Actual } \\
\text { availa- } \\
\text { bility } \\
\end{array}$ & Kind & \multicolumn{2}{|l|}{$\begin{array}{l}\text { Actual } \\
\text { availa- } \\
\text { bility }\end{array}$} & Kind & \multicolumn{2}{|l|}{$\begin{array}{l}\text { Actual } \\
\text { availa- } \\
\text { bility }\end{array}$} \\
\hline 1 & \multirow{7}{*}{ First } & \multirow{4}{*}{ Existing } & \multirow{7}{*}{ Second } & \multirow{4}{*}{ Existing } & \multirow{7}{*}{ First } & \multicolumn{2}{|c|}{ Non-existent } & \multirow{7}{*}{ Second } & \multicolumn{2}{|c|}{ Non-existent } \\
\hline 2 & & & & & & \multirow{3}{*}{ Existing } & Real & & \multirow{3}{*}{ Existing } & Real \\
\hline 3 & & & & & & & Real & & & Potential \\
\hline 4 & & & & & & & Potential & & & Potential \\
\hline 5 & & Existing & & $\begin{array}{l}\text { Non- } \\
\text { existent }\end{array}$ & & \multirow{3}{*}{\multicolumn{2}{|c|}{ Non-existent }} & & \multirow{3}{*}{\multicolumn{2}{|c|}{ Non-existent }} \\
\hline 6 & & $\begin{array}{l}\text { Non- } \\
\text { existent }\end{array}$ & & Existing & & & & & & \\
\hline 7 & & $\begin{array}{l}\begin{array}{l}\text { Non- } \\
\text { existent }\end{array} \\
\end{array}$ & & $\begin{array}{l}\begin{array}{l}\text { Non- } \\
\text { existent }\end{array} \\
\end{array}$ & & & & & & \\
\hline
\end{tabular}

Therefore, the objects of ownership (specified objects of the second kind) are distinguished within the framework of the system of ownership relations; the subjects of ownership or the owners (objects of the first kind); and ownership relations are a combination of some selected connections of the first kind. These connections regulate the framework for the implementation of the effects reflected by the bonds of the second kind. We see the following from Table 5:

$\checkmark$ the first type of connection may or may not exist, there is a three-variant multiplicity in the case of their existence;

$\checkmark$ connections of the second kind can be arbitrary from among the possible ones for the corresponding combinations (2-3) or predefined (combination 4) with their presence. Therefore, they do not carry the load of demarcation;

$\checkmark$ connections between non-existent objects are absent.

It should be noted that the structuring introduced is relatively simplified and adapted for use at the level of traditional scientific research and practical development. We consider now the structural dynamics of the system of property relations or its dynamic structuring. The system of property relations is dynamic in all its structural aspects. The dynamism of the system of property relations can be expressed both in 
the dynamism of its individual components and in their complex dynamism. This dynamism can consist in changing over time:

$\checkmark$ the composition of the subjects of ownership;

$\checkmark$ the composition of ownership objects;

$\checkmark$ the ownership relations in terms of the transformation of rights and liability restrictions.

Therefore, we can have a transformation of the composition of objects of the first and second kind, as well as the connections of both genders in terms of their presence, absence and character. We consider the structural dynamics of ownership relations on the example of two neighboring points in time, the next and the previous, among which the second comes after the first, naturally.

The transformation of objects and connections has the meaningful content in this case, presented in Table 6, where "C" is connected, "NC" is not connected, "R" is really and "P" is potentially. The contouring highlighted the cases in Table 6 , there are both an object of the first kind and an object of the second kind, which may have a connection among themselves. In the case of the absence of at least one of them, such a relationship cannot exist in principle.

\subsection{Typical dynamic procedures of the system of ownership relations}

We note that it is the principled dynamism of property relations, the observability and controllability of the respective objects, that serve as the fundamental basis for the feasibility, purposefulness and effectiveness of marketing, which is inextricably linked to the change in property relations caused by contractual conditions. In fact, marketing involves (in the implementation plan) the transfer of ownership of the object of ownership by the previous owner to another person, the new owner (see Figure 2). The assignment (reimbursement) does not take place in the case of the non-repayable nature of this transfer of ownership or the benefit of the intangible nature of the counterclaim, and it is made in the case of compensable. Accordingly, we can see before this transfer the following:

$\checkmark$ the first owner has a real connection of the first kind with his object of ownership (the first object of ownership) and does not have a connection of the first kind or has it in a potential variant with the object of ownership of the second owner (with the second object of ownership);

$\checkmark$ the second owner has a real connection of the first kind with his object of ownership (the second object of ownership) and does not have a connection of the first kind or has it in a potential variant with the already mentioned object of ownership of the first owner (with the first object of ownership). 
Table 6. The structural dynamics systems of ownership relations

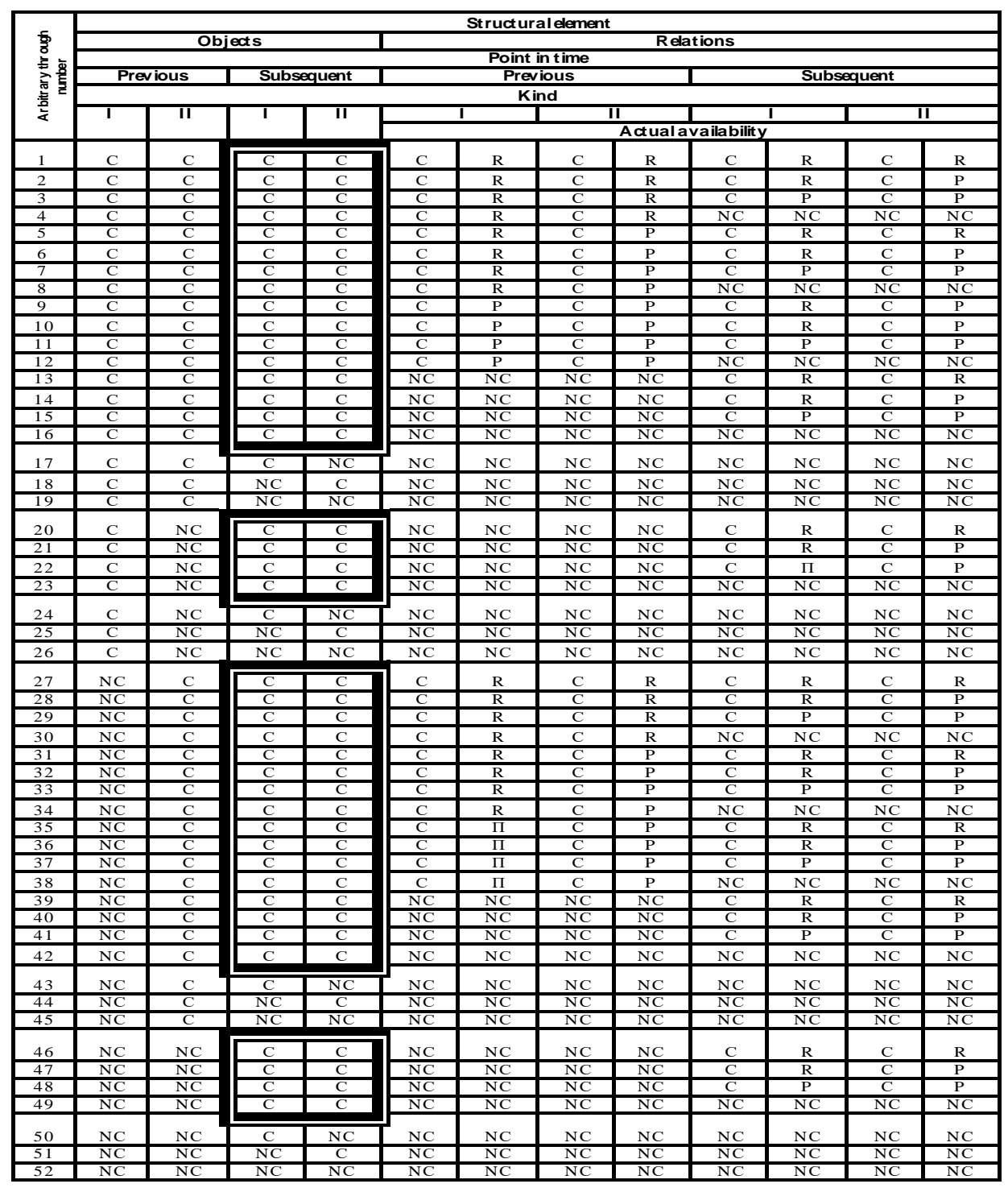

$\checkmark$ the second owner has a real connection of the first kind with his object of ownership (the second object of ownership) and does not have a connection of the first kind or has it in a potential variant with the already mentioned object of ownership of the first owner (with the first object of ownership). 
Figure 2. Structural dynamics of the system of ownership relations in the process of transfer of ownership

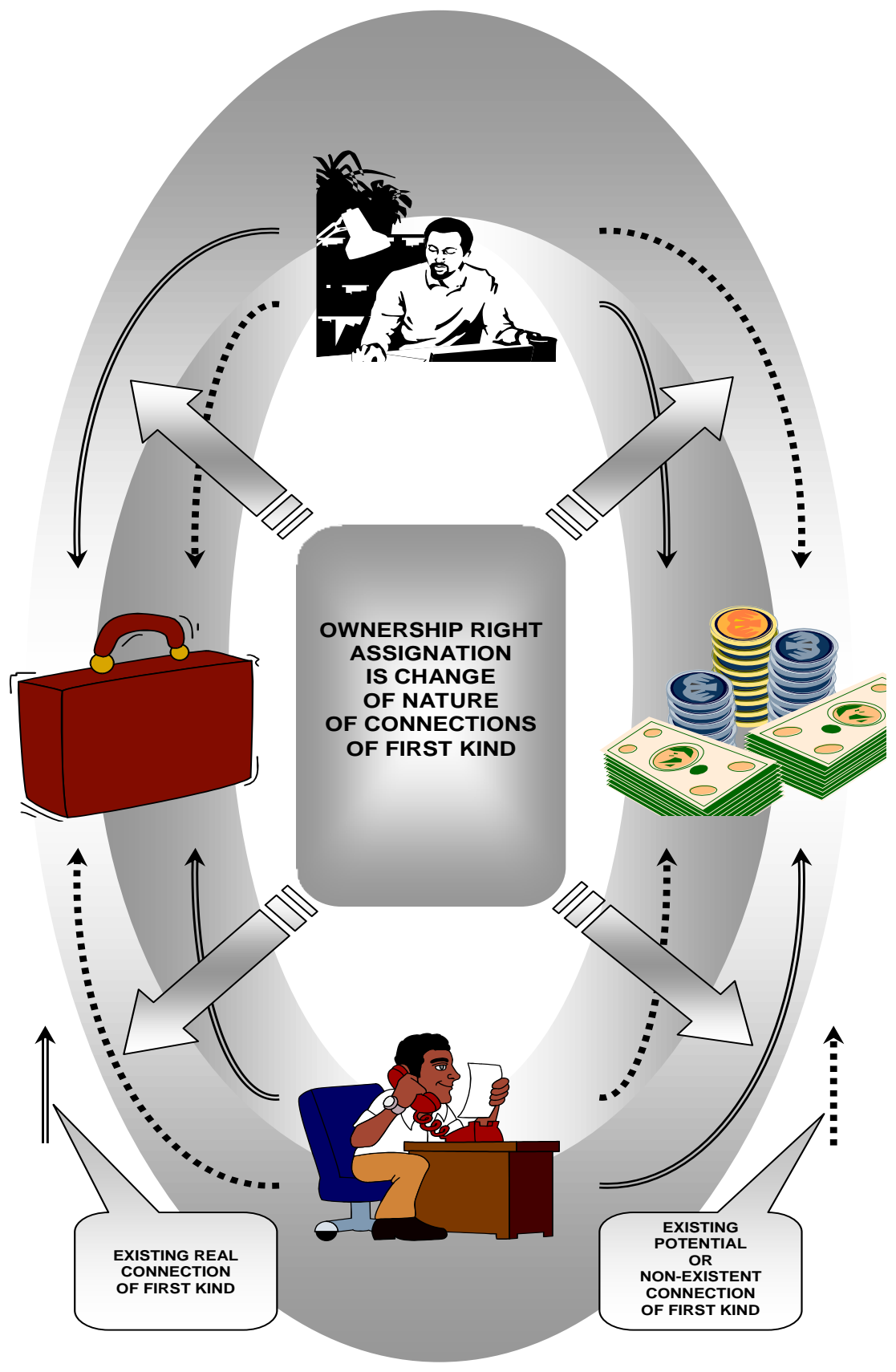


We can see the following after this transfer:

$\checkmark$ the first owner makes the real connection of the first kind with the first object of ownership into the potential one or makes it non-existent, but it has a real connection of the first kind with the second object of ownership;

$\checkmark$ the second owner makes the real connection of the first kind with the second object of ownership into the potential one or makes it non-existent, but it has a real connection of the first kind with the first object of ownership.

Therefore, the transfer of ownership rights can be either one-sided or mutual, but in but in reality, most often there is mutual or multiple assignment. Moreover, multiple assignment can be represented in a scenario as a set of mutual assignments. Thus, it is possible to create scenarios for the assignment of ownership rights of any level of hierarchy and complexity.

The dynamics of the system of ownership relations is variable and significantly affects the state of the operators of the sphere of implementation of ownership relations. Therefore, it can be optimized. The ownership can arise (be acquired), change and disappear (cease). Therefore, the transfer of property rights can be either one-sided or mutual. The ownership can arise (be acquired), change and disappear (cease). The emergence (or acquisition) of ownership occurs taking into account Chapter 14 of the Civil Code of the Russian Federation in the following cases:

$\checkmark$ according to the current legislation, directly and without alternative the owner is appointed;

$\checkmark$ according to the decision of the competent judicial body, which entered into legal force and determines the new owner;

$\checkmark$ according to a unilateral decision of the former owner (for example, by way of donation, inheritance or by succession), hereinafter under the current legislation;

$\checkmark$ according to an agreed decision of the group of owners, including the former and new owner; this occurs in the course of the fulfillment of obligations under the contract as a rule;

$\checkmark$ when creating or manufacturing a property object by a subject of ownership; for example, in order to extrapolate the statutory provisions of Article 218 of the Civil Code of the Russian Federation, which determines such an order for things. At the same time, legal restrictions are introduced here related to processing operations under Article 220 of the Civil Code of the Russian Federation, which are used in the production of the customer-supplied raw materials (for the so-called tolling operations);

$\checkmark$ when applying to the property of publicly available for the collection of things in accordance with Article 221 of the Civil Code of the Russian Federation; 
$\checkmark$ when contacting the property of ownerless things in accordance with Article 225 of the Civil Code of the Russian Federation, stray animals and in some other cases.

A change or disappearance (termination) of the property rights may occur in similar cases, namely:

$\checkmark$ according to the current legislation, directly and without alternative changing the owner, i.e. altering the system of property relations in favor of another person, including in favor of the most legislative subject of the international law or depriving the previous owner of the property rights in general, converting the property object that previously belonged to him to the property into the ownerless property or non-existent through its destruction;

$\checkmark$ according to the decision of the competent judicial authority, which has entered into legal force and changes the owner or deprives the owner of the property;

$\checkmark$ according to the unilateral decision of the former owner;

$\checkmark$ according to the agreed decision of the group of the owners in the framework of the contract execution.

In addition, the ownership termination may occur in the case of property disappearance or termination of the subject of ownership. Thus, the emergence, change and termination of property rights occur within the framework of the situational paradigm " $7+4+6$ " in Russia. The above considerations lead to the following conclusions:

$\checkmark$ system localizations and orderings can be represented through conceptual descriptive structures of the system of ownership relations which exist in the modern economy, including the Russian economy, both in a static and dynamic form in the form of multiple orderings, including inter-set orderings;

$\checkmark$ the introduction of a system of ownership relations allows us to adequately interpret economic management situations and then proceed to the analysis and synthesis of managerial organizational and economic mechanisms;

$\checkmark$ the identified system of ownership relations allows to specify the typological features of the economy, characteristic of the regions of the world and the country, individual countries, regions and communities of individuals, legal entities, and persons with special status;

$\checkmark$ identification of the ownership relations system allows organizing general environment management at the macrolevels, mesolevels and microlevels, including the adaptation of legislation and internal corporates, enterprises and departments regulations. 
We consider that those issues of managing the institutional economy of the system of ownership relations require additional optimization.

\subsection{Decomposition of ownership relations}

There is no doubt that the system as a component of the ownership relations makes possible to describe the whole diversity of economic and civil-legal connections. Therefore, it is advisable to move from the six-component system of proprientary interest relations to a one-component structure, retaining only the system of ownership relations, through which it is possible to form necessary civil relations in terms of objects of proprientary interest law.

It is possible to decompose these relations by highlighting the rights of possessions, rights of use and rights of disposal within the framework of the ownership relations system. In this sense, ownership relations will be made up of three basic types of ownership rights, providing all seven possible versions (separate rights, pairwise combinations and the threefold combination).

Unfortunately, the content of the right of possessions, the right of use and the right to disposal are essentially not defined in Russia. Therefore, the following author's interpretation is proposed:

$\checkmark$ rights possession are the possessor's ability to carry out actions or omissions in respect of the object of possession in a non-legal manner;

$\checkmark$ rights of use are the user's ability to implement in a non-legitimate manner the consumption of the use object without a significant change in its consumer properties;

$\checkmark$ rights of disposal are the disposer's ability to assign, in a non-illegal manner, the rights of possession, use and disposal in relation to the object of disposal.

Having considered the system of ownership relations as a system with environmental, structural and procedural representation, it is possible to set and solve the tasks of its environmental, structural and procedural optimization by implementing the conceptual scheme of the feasibility study of the corresponding management decisions (Dmitriev, 2018a; 2018b; 2002a; 2002b).

\subsection{Implementation application development}

The considered results were successfully applied in practice (Dmitriev, 2002a; Dmitriev \& Gutkina, 2004; Dmitriev \& Burdin, 2006; Dmitriev et al., 2002), including the following projects:

$\checkmark$ when organizing and selling products of special authoring software in the form of a software implementation of a simulation model, there were parks with an emphasis on the aviation sector in the period 1984-1991. The sales 
volumes for the proposed reusing projects were, in terms of current prices, of about US \$ 1.5 million per year, which was a very impressive financial result for a department as sector of a research institute with less than 10 employees;

$\checkmark$ in carrying out developments in the field of justifying the feasibility of improving the reliability of the parks of the final and component parts of aviation equipment, as well as their transfer to advanced strategies for technical operation in the period 1984-1991 by a significant number of nomenclature positions, counted in dozens of types of products per year;

$\checkmark$ during the formation of the intersectoral system (the aviation industry of the USSR, the civil aviation of the USSR), the system of orders and deliveries of aviation technical equipment (aircraft engines, spare parts, operational and maintenance group kits) in the mid-1980s;

$\checkmark$ in the formation of proposals for reforming the tax system in the interests of the Moscow Council at the turn of the 1990s and in relation to the field of joint projects for the production of civil aircraft in the 1990s;

$\checkmark$ with consulting support of the activities of the associative group of Russian aviation and space insurers in the period 1992-2000, as well as a number of insurance companies in a retrospective analysis of the prerequisites for initiating false insurance cases and in assessing the extent of property damage to aviation insurers;

$\checkmark$ when publishing author's articles and books in the period 1978-2018 (the total number of publications is more than 350, including more than 50 monographs and textbooks), as well as during the preparation, conclusion and execution of a number of high-budget contracts for the implementation of research in the same period;

$\checkmark$ when forming the presentation of typical mechanisms of dynamic transformation of property objects in the framework of leasing and rental operations in the 2000 s;

$\checkmark$ during the formation of corporatization projects (forming the holdings of both kinds) in a number of high-tech industries in Russia (more than 10 projects) with an emphasis on the aviation industry, as well as in the formation of proposals for their internal corporate self-government in the period 1996-2012;

$\checkmark$ in the preparation of numerous normative legal acts, including bills related to ownership relations, and during their experting in the period 1978-2002;

$\checkmark$ when conducting training sessions in the system of higher education and staff development. Thus, the author delivered courses on "Organization of entrepreneurial activity" and "Theory of Organization" in 1998-2018 at the Moscow Aviation Institute (National Research University) with an annual coverage of a contingent of more than 1,000 students per year. Lectures on property relations for the Directorate and the reserve of the Directorate of Enterprises at the Institute of Advanced Training of High-Tech Enterprises (Korolev City, Moscow Region) in the period 1998-2012 were read regularly. The coverage was several hundred listeners per year. 


\section{Conclusions}

The stated considerations give objective reasons to formulate the following statements, conclusions and recommendations:

1) At present, the systems of ownership relations in the world in various countries are not harmonized, they are practically not represented, they are legally described with serious flaws and they have an ambiguous vision on the part of operating owners. A typical negative example in this sense is the Russian system of ownership relations. This generates significant losses due to the occurrence of management errors caused by the inadequately identified processor of the object of management and does not allow improving the system of ownership relations, which is practically a black box, sporadically and empirically transformed. The negative state of the system of ownership relations is a serious crisis-forming factor and prevents the globalization of economic and legal spaces due to the basic nature of the economic basis of society.

2) The Russian system of ownership relations should be subject to strict scientific processor identification in terms of statics and dynamics of its state, optimization (rationalization at the first stage) and adaptation to the ownership relations systems of countries with which developed economic relations are maintained or planned to maintain. The prototype of such a presentation is demonstrated in a sufficiently complete in scientific terms and in a form suitable for practical application.

3) The system of ownership relations is represented through the system of real and potential subjects of ownership, objects of ownership and ownership relations between them. They are fixed in statics and they are transformed in dynamics in a typical way.

4) It is advisable to introduce a unified global representation of the system of ownership relations, both substantive and legal.

5) The system of ownership relations allows optimization.

6) Experience in testing development should be recognized as scientifically positive and useful in the applied aspect. Therefore, there are grounds for asserting that the prototype of such a presentation is demonstrated in a sufficiently complete form in scientific terms and in a form suitable for practical application.

\section{References:}

Al'pidovskaya, M.L. \& Sokolov, D.P. 2015. Ownership Relations in Modern Russia: Genesis, Problems and Perspectives. Monography. Kostroma: Kostroma State University Publishing House.

Bodrunov, S.D., Dmitriev, O.N. \& Koval'kov, Ju.A. 2002. Aviation industry of Russia 
on eve of the 21st century: Problems of effective management (Part 1 and Part 2), Monography. SPb.: Aerospace Equipment Corporation Publishing House.

Dmitriev, O.N. 2018a. Conception of engineering-system design and redesign of Russian legislative space as realization sphere of enterprises life cycle. Microeconomics, 2, 48-57.

Dmitriev, O.N. \& Novikov, S.V. 2018. Transformation of Russian tax system as a part of integration of economy into international high-technology production field of socioeconomic systems. European Research Studies Journal, XXI, 4, 400-413.

Dmitriev, O.N. 2018b. System-engineering performance of management task of tax system environments optimization of Russian high-tech industrial enterprises operating. Microeconomics, 4, 15-26.

Dmitriev, O.N. 2002a. System analysis in management. Moscow: Gnom \& D Publishing House, 3rd edition, in Russian and in English.

Dmitriev, O.N. 2002b. Intellectual information technology for feasibility studies of marketing decisions. M.: Gnom \& D Publishing House, Printed version of thesis of full-doctor of economic sciences, 08.00.13.

Dmitriev, O.N. \& Gutkina, A.V. 2004. Civil aviation engines lease charging. Monography, M.: Gnom \& D Publishing House.

Dmitriev, O.N. \& Burdin, A.K. 2006. Corporate leasing management. Monography, M.: KnoRus Publishing House.

Dmitriev, O.N., Khomyakov, D.I., Ershevich, P.V. \& Arkhipov, F.V. 2002. Optimization of leasing operations, Monography, M.: Gnom \& D Publishing House.

Grabova, O.N. 2007. Dynamics of economic relations. Kostroma: Kostroma State University, Dissertation of the Doctor of Economic Sciences (Full-Doctor, Economics), 08.00.01.

Gutman, G.V. et al. 2002. The system of ownership relations in a market economy. Monography. Kostroma: Kostroma State University Publishing House.

Sukhanov, E.A. 1991. Lectures on ownership rights. M.: Legal literature Publishing House.

Tsorgaeva, M.B. 2014. Transformation of ownership relations in the information economy, $\mathrm{SPb}$ : St. Petersburg State University of Economics, Dissertation of the Candidate of Economic Sciences (Ph.D., Economics), 08.00.01.

Yakunina, I.N. 2006. Economic relations of ownership: A mechanism for harmonizing interests. Tambov: Dissertation of the Candidate of Economic Sciences (Ph.D., Economics), 08.00.01.

Zolotova, V.A. 2017. Management problems and tasks of the formation of management innovation anti-crisis program in the Russian high-tech industry. Monography. M.: KnoRus Publishing House. 